\title{
Decision Support System for Subject Allocation to Faculty
}

\author{
Abhilash Shukla ${ }^{1}$ and Dhatri Raval ${ }^{2}$ \\ Department of Computer Science and Applications, Charusat University, Changa, Gujarat, India ${ }^{1,2}$
}

\begin{abstract}
In the Smt. Chandaben Mohanbhai Patel Institute of Computer Applications, Charusat, allocation of subjects to faculties at the start of each new semester of academy year is a complex and tedious process. We propose a decision support system that attempts to maximize satisfactions for the overall faculty group. The system is able to improve the satisfaction level to $80 \%$, even though some of the subjects may be heavily prioritized by faculty. Concept of Data Mining is used and it is shown to be effective. Results of subject allocation by the system have been positive. The system will greatly reduce the complex manual work of Principal/HoD for subject allocation. In addition, it will result in significant time saving for the Institute's Subject Allocation Committee.
\end{abstract}

Keywords: Subject Allocation, Decision Support System, Faculty Members.

\section{INTRODUCTION}

In any institute, Principal/ HOD/ Higher Authority/ Timetable committee has to assigned subjects to faculty before starting of the new semester of the academic year. In this process subject allocation committee has to consider many points like interest of faculty in subject, feedback of faculty over subject, capability of faculty to take new introduced challenging subject and so other points so that students will get the best knowledge from a faculty who is expert in the subject. Subject allocation committee has to do tedious, complex manual work for this which takes lots of time to do an analysis before assigning any subject to any faculty.

Through this application will be developed for allocating subject to faculty in which concept of data mining will be implemented.

\section{SYSTEM WORKFLOW}

First all faculty members have to provide their choice base on which system will create Subject Priority Matrix. After the input given system will calculate SAP - Subject Assign Point base on which subject allocation will be done.

\section{A. System Input}

At the starting of the new semester, subject priority will be taken from all faculties which they want to teach in new semester. In first phase, faculty has to give priority rank from one to five from all subjects of each semester of all programs. Figure1 shows all the subjects short name of all semester of all programs from which faculties have to give semester wise priorities. After providing semester wise priority, faculty has to give over all priority from subjects selected in the first phase. Figure2 shows how it will take overall priority from faculty.

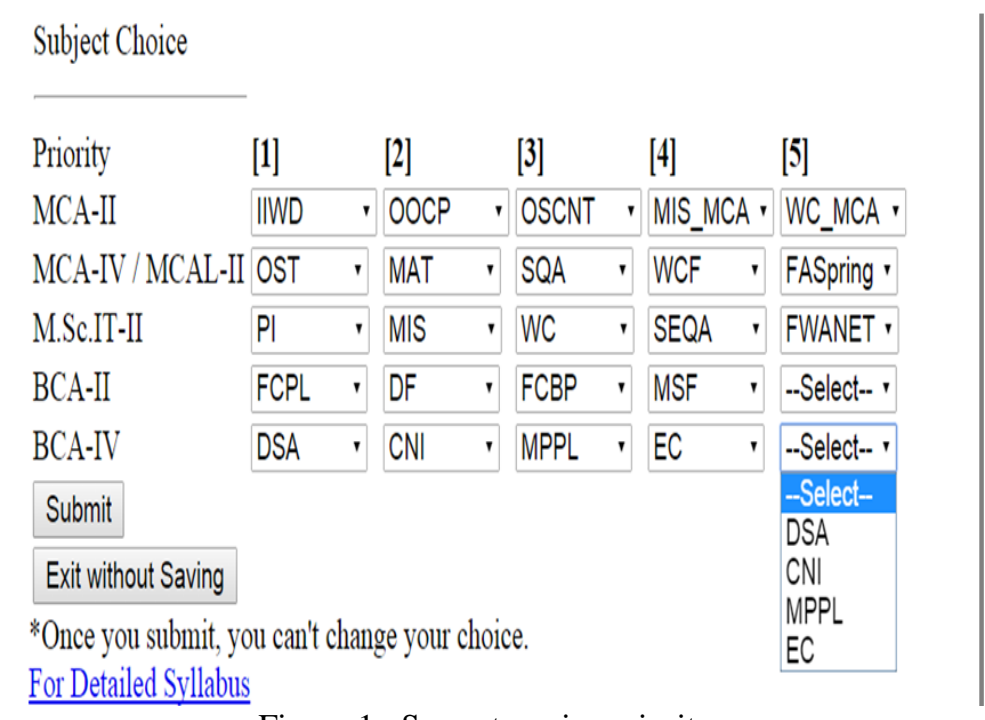

Figure 1. Semester wise priority 
Vol. 5, Issue 12, December 2016

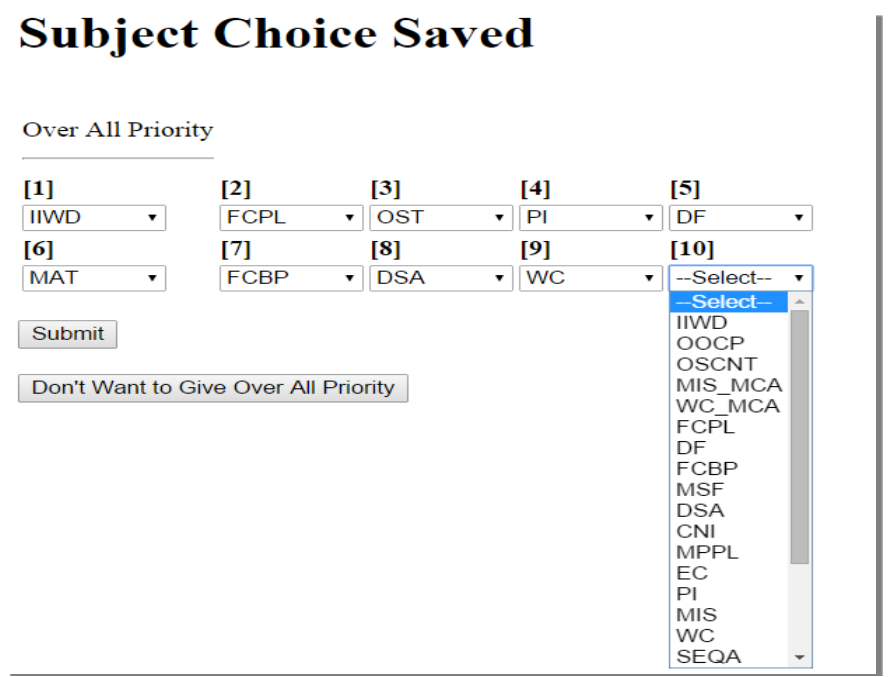

Figure 2. Over all priority

Base on above inputs semester wise subject allocation report generate automatically by system which helps subject allocation committee to take a decision.

\section{B. Subject Allocation Parameter}

Following parameters will be taken into consideration in allocation of subject.

- Student feedback for faculty over a subject will be an essential thing in deciding whether the subject will allocate or not to that particular faculty.
- In case of new introduced subject, the system will check the faculty's technical profile and subject profile before allocating subject.

- If institute follow rotation policy, then system wills not allocation any subject to faculty more than two times in continuation.

- In case multiple faculty assigned for same subject, then system will consider the wish list taken prior from Principal/HOD.

- Subject credit, no of division/batch/student for a semester also analyse by the system to decide no of faculty required for subject.

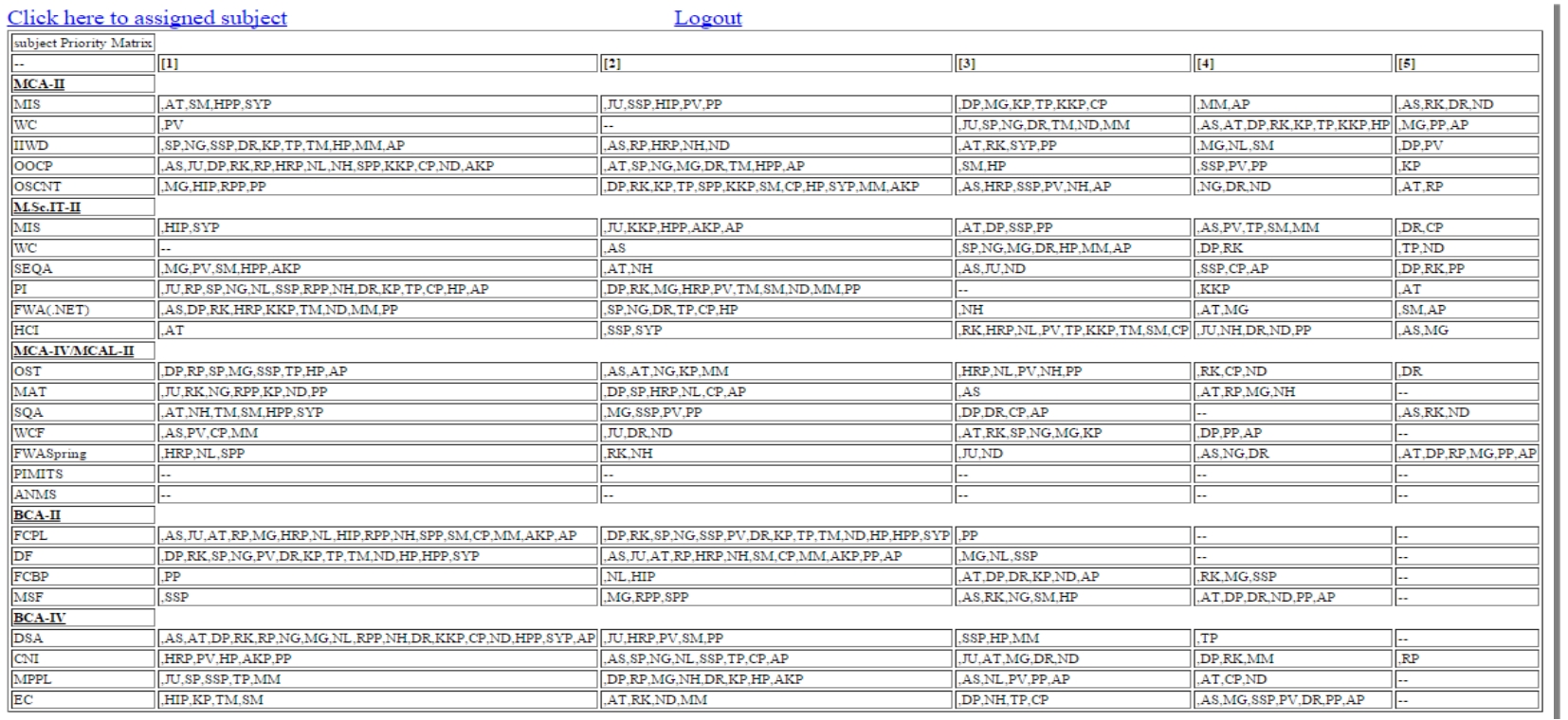

Figure 3. Subject Priority Matrix

\section{Calculation of SAP - Subject Assign Point}

Based on SAP- Subject Assign Point allocation will be done by the system. This SAP is calculated for all subjects for all faculties which mean faculties who obtain highest SAP for particular subject than there is more possibility of assigning that particular subject to that faculty.
$\mathrm{SAP}=\mathrm{SSP}+\mathrm{OSP}+\mathrm{ST}+\mathrm{SF}+\mathrm{PW}+\mathrm{FP}$

SSP: indicate Semester Subject Priority

OSP: indicate Over All Subject Priority

ST: indicate Subject Taken Point

SF: indicate Semester Feedback

PW: indicate Principal Wish list Point (in case of same 
SAP obtain by faculty)

FP: indicate Faculty Profile point (in case new subject introduce in the semester)

\section{i. Calculation of SSP}

SSP will range from 10 to 50 with the interval of 10 . If any faculty giving first priority to any subject then 50 points will take into consideration. The point will decrease by 10 as per priority decrease.

Table 1: Calculation of SSP

\begin{tabular}{|l|l|}
\hline Priority & Point \\
\hline 1 & 50 \\
\hline 2 & 40 \\
\hline 3 & 30 \\
\hline 4 & 20 \\
\hline 5 & 10 \\
\hline Priority not given & 00 \\
\hline
\end{tabular}

\section{ii. Calculation of OSP:}

OSP will range from 10 to 60 with the interval of 10 . OSP only been calculated if SSP is not zero. Faculty can provide overall priority from 1 to 10 to the subject selected in the first phase.

Table 2: Calculation of OSP

\begin{tabular}{|l|l|}
\hline Over All Priority & Point \\
\hline 1,2 & 60 \\
\hline 3,4 & 50 \\
\hline 4,5 & 40 \\
\hline 6,7 & 30 \\
\hline 7,8 & 20 \\
\hline 9,10 & 10 \\
\hline Priority not given & 00 \\
\hline
\end{tabular}

\section{iii. Calculation of ST:}

ST will range from 0 to 30 with the interval of 5 .

Table 3: Calculation of OSP

\begin{tabular}{|l|l|l|}
\hline $\begin{array}{l}\text { No. of time } \\
\text { subject taken }\end{array}$ & $\begin{array}{l}\text { Point Rotation } \\
\text { policy apply }\end{array}$ & $\begin{array}{l}\text { Point Rotation } \\
\text { policy not apply }\end{array}$ \\
\hline 0 & 25 & 0 \\
\hline 1 & 20 & 5 \\
\hline 2 & 15 & 10 \\
\hline 3 & 10 & 15 \\
\hline 4 & 5 & 20 \\
\hline 5 & 0 & 25 \\
\hline$>=6$ & - SAP & 30 \\
\hline
\end{tabular}

\section{iv. Calculation of SF:}

Subject Feedback is the most important parameter in the calculation of SAP.

Table 4: Calculation of SF

\begin{tabular}{|l|l|}
\hline $\begin{array}{l}\text { No. of time subject } \\
\text { taken }\end{array}$ & $\begin{array}{l}\text { Point Rotation policy } \\
\text { apply }\end{array}$ \\
\hline$>=80$ & 100 \\
\hline$>=70$ and $<80$ & 80 \\
\hline
\end{tabular}

\begin{tabular}{|l|l|}
\hline$>=65$ and $<70$ & 60 \\
\hline$>=60$ and $<65$ & 40 \\
\hline$>=55$ and $<60$ & 00 \\
\hline$>=50$ and $<55$ & -25 \\
\hline$<50$ & -50 \\
\hline New Subject & 00 \\
\hline
\end{tabular}

v. Calculation of PW:

Principal wish list take into consideration if subject allocated to a number of faculty more than it require

Table 5: Calculation of PW

\begin{tabular}{|l|l|l|}
\hline Principle & Yes & No \\
\hline $\begin{array}{l}\text { Subject listed in principal wish } \\
\text { list for faculty }\end{array}$ & 05 & 0 \\
\hline
\end{tabular}

\section{vi. Calculation of PW:}

This parameter is only used for newly introduce subject.

Table 6: Calculation of FP

\begin{tabular}{|l|l|l|}
\hline & Yes & No \\
\hline $\begin{array}{l}\text { Subject Profile match to Faculty } \\
\text { Profile }\end{array}$ & 50 & 0 \\
\hline
\end{tabular}

\section{CONCLUSIONS}

From the all above calculation this system is able to improve the satisfaction level to $80 \%$. From the given data person can also analyse the subject selection process of any person. This system reduces paper work nearby $90 \%$. It is easy to use system and show error less output.

\section{ACKNOWLEDGMENT}

The Author of this paper would like to acknowledge Dr. Atul Patel, Dean and Principal, Smt. Chandaben Mohanbhai Patel Institute of Computer Applications, CHARUSAT, for his encouragement to perform this type of decision support system and for all his useful comments on the writing of this paper. Thanks to Prof. Mahesh J. Shukla, Associate Professor, J. \& J. College of Science, for his motivation and guidance to write this paper. Finally, many thanks to all colleagues for their direct and indirect help.

\section{REFERENCES}

[1] Saaty, T. L. (2006), Fundamentals of Decision Making and Priority Theory with the Analytic Hierarchy Process, Pittsburgh: RWS Publications

[2] Luan, Jing. "Data mining and its applications in higher education" new directions for institutional research, vol. 2002 no. 113, pp. 17$36,2002$.

[3] Alvarez-Valdes R., Crespo E., \& Tamarit J.M. (2002). Design and implementation of a course scheduling system using tabu search. Eur J Opnl Res, 137:512-523.

[4] Clemen G. (1996). A Rule-Based Expert System Approach to Academic Advising. Innovations in Education and Teaching Janssen M.K. (1995). The Next Generation of ComputerAssisted Advising and Beyond, NACADA Journal, 16 (1), 47- 50. 